\title{
Plasma Inflammatory Cytokines as Predictor Markers for Severity of Histological Variations of Intestine among Celiac Patients
}

\author{
Abangah Ghobad ${ }^{1}$, Asadollahi Ruhangiz ${ }^{2}$, Rahmani Asghar ${ }^{3}$, Asadollahi Khairollah ${ }^{4,5, *}$, Teimouri hadi $^{3}$ \\ ${ }^{1}$ Department of Gastroenterology, Faculty of Medicine, Ilam University of Medical Sciences, Ilam, Iran \\ ${ }^{2}$ Department of Patology, Faculty of Medicine, Ilam University of Medical Sciences, Ilam, Iran \\ ${ }^{3}$ Student researches committee, Ilam University of Medical Sciences, Ilam, Iran \\ ${ }^{4}$ Department of Epidemiology. Faculty of Medicine, Ilam University of Medical Sciences, Ilam, Iran \\ ${ }^{5}$ The researches centre of Psychosocial injuries, Ilam University of Medical Sciences, Ilam, Iran \\ *Corresponding author: masoud_1241@yahoo.co.uk
}

Received March 18, 2014; Revised April 11, 2014; Accepted May 11, 2014

\begin{abstract}
Background: Celiac is a chronic hereditary intestinal disorder caused by autoimmune stimulation and injury of intestinal mucosa and different studies have reported an increase of inflammatory cytokines production in these patients. This study aimed to investigate the serum level of inflammatory cytokines and their correlations with the severity of histological variations among celiac patients. Material and methods: By a cross sectional study all celiac patients attending to gastrointestinal clinics in Ilam city during Oct. 2011- MAR. 2013 were investigated. Demographic data was collected using a validate questionnaire and patient's interview and each patient was taken a blood sample for laboratory investigation of tTG-IgA antibody via ELISA test and the serum level of hsCRP, IL-6 and TNF-a was measured. All patients underwent endoscopic evaluation and biopsy samples were evaluated according to Marsh classification and correlation between severity of histological variations and serum levels of inflammatory cytokines was measured. Results: Totally 274 patients including 90 male and 184 female with a mean age of $28.8 \pm 14.4$ years were evaluated. The mean serum levels of hs-CRP, IL-6 and TNF-a were $7.8 \pm 3.1 \mathrm{mg} / \mathrm{l}, 2.6 \pm 0.9 \mathrm{pg} / \mathrm{ml}$ and $6.9 \pm 4.6 \mathrm{pg} / \mathrm{ml}$ respectively $(\mathrm{p}=0.599, \mathrm{p}=0.629$ and $\mathrm{p}=0.651)$. Hs-CRP showed a significant relationship with the severity of mucosal damage upon class I of Marsh classification $(\mathrm{p}=0.01)$; however, IL-6 showed a significant level among patients with Marsh I, II and IIIC ( $\mathrm{p}=0.000, \mathrm{p}=0.02$ and $\mathrm{p}=0.000)$ but not in those with Marsh class IIIA and IIIB. Conclusion: There was a positive relationship between mean serum levels of IL-6 and TNF-a with increasing the Marsh classification from class I to class IIIC and the highest rate of IL-6 and TNF-a was shown in Marsh IIIC but the serum level of hs-CRP was not increased with Marsh class increasing. It was concluded that as the Marsh classification increased from class I to class IIIC, and/or the severity of pathologic variations was increased, the mean serum levels of inflammatory markers were increased too.
\end{abstract}

Keywords: Celiac, hs-CRP, IL-6, TNF-a, Marsh classification

Cite This Article: Abangah Ghobad, Asadollahi Ruhangiz, Rahmani Asghar, Asadollahi Khairollah, and Teimouri hadi, "Plasma Inflammatory Cytokines as Predictor Markers for Severity of Histological Variations of Intestine among Celiac Patients.” International Journal of Celiac Disease, vol. 2, no. 2 (2014): 54-57. doi: 10.12691/ijcd-2-2-6.

\section{Introduction}

Celiac disease is a chronic hereditary disorder caused by damages of intestinal mucosa due to consumption of foods with gluten [1]. A classic definition of celiac is a disease accompanied with villous atrophy and malabsorption signs such as steatorrhea, weight loss and other food related symptoms which will be cured during several weeks after gluten free regimen [2]. According to the Modified Marsh classification the pathologic variations of intestinal mucosa is divided into 5 categories including Marsh I (secretion of lymphocytes inside the lamina propia and >40 intraepithelial lymphocytes/ 100 epithelial cells), Marsh II (hypertrophy of crypts without villous atrophy), Marsh IIIA (partial villous atrophy), Marsh IIIB (subtotal villous atrophy) and Marsh IIIC (total villous atrophy) [3]. Development of these pathologic variations is associated with the sensitivity and reaction rates of patients to gluten and improvement of these variations is associated with the elimination of gluten in their daily regimens [4]. TCD4 cells sensitive to gluten, via secretion of INF-c, cause activation of preinflammatory responses such as metalloproteinase activation that result in mucosal damages and villous atrophy. Also, metalloproteinase causes TNF-a secretion from intestinal myofibroblasts [5]. Studies on $\mathrm{T}$ cells of intestinal lamina propia reported that cytokines profile in celiac patients are mostly consisted TNF-a and INF-C [6]. 
Cytokines are the intracellular proteins that have main roles in the regulation of immunology and inflammatory reactions of body [6,7]. Also CRP is a systemic inflammatory biomarker that is widely used for the diagnosis of acute or chronic inflammatory diseases [8] and its laboratory measurement is easy, inexpensive and accessible [4]. This marker has a predictor role for inflammation and malignancy and its serum level is increased during different malignancies. Prospective studies have shown the higher risk of malignancy among patients with higher serum level of CRP $[9,10,11]$. This marker is appeared in peripheral blood after infection, trauma, myocardial diseases and inflammatory diseases, such as rheumatoid arthritis, Crown's disease, and it is produced by liver in response to inflammatory cytokines such as IL1, TNF-a and IL6 [11,12]. Studies have shown that the production rate of cytokines by immunological cells of mucosa is associated with the severity rate of mucosal cells damages in celiac patients [13]. This study aimed to investigate the serum level of inflammatory cytokines and their correlations with the severity of histological variations among celiac patients.

\section{Material and Methods}

\subsection{Patients Selection}

By a cross-sectional study all patients attended to gastrointestinal clinics in Ilam city, west of Iran, during Oct. 2011 to April 2013 with a history of celiac symptoms were evaluated and those with confirmed diagnosis of celiac were entered into the study. Celiac disease was defined as a digestive disease caused by an immune reaction to eating gluten and this reaction produces inflammation that damages the small intestine's mucosa and prevents absorption of some nutrients resulting in

weight loss, bloating and sometimes diarrhea. Using a validated questionnaire demographic data of participants were collected via patients' interview. Each patient was taken a sample of venous blood and samples were sent to a reference laboratory for ELISA testing of tTG- IgA antibody. Serologic amounts more than $25 \mathrm{U} / \mathrm{ml}$ were considered as sero-positive. Excluding criteria were serum level of tTG-IgA antibody less than $25 \mathrm{U} / \mathrm{ml}$, IgA deficiency, patients with liver diseases, autoimmune disorders and IBD.

\subsection{Laboratory Investigations}

Serum level of hs-CRP was measured using Pars Azmon kits and serum levels of IL6 and TNF-a by Bender Kits, all via ELISA method.

\subsection{Endoscopic and Pathologic Evaluations}

All patients underwent upper endoscopic evaluations, using Olympus endoscopic equipment and each patient was taken 4 biopsy samples of intestinal mucosa in different sections of second part of duodenum. Biopsy samples were then sent for pathological investigations and Marsh classifications by an expert pathologist upon Modified Marsh classifications.

Demographic and laboratory data were then entered into SPSS 16 and mean \pm SD of serum levels of different markers were measured. Quantitative and qualitative data were tested using $\mathrm{T}$ - test and ANOVA respectively and correlations between mean serum levels of different markers and mucosal damages were tested using Pearson correlation coefficient test. A p-value less than 0.05 was considered as significant.

\section{Results}

Table 1. Frequency of different classes of intestinal involvements and mean serum levels of different markers according to gender in celiac patients

\begin{tabular}{|c|c|c|c|c|c|}
\hline Variable & Male & Female & Total & P value \\
\hline Mean age (year) & & 27.36 & 29.54 & 28.82 & 0.24 \\
\hline Gender (n) & 90 & 174 & 284 & 0.03 \\
\hline \multirow{3}{*}{ Marsh classification number (\%) } & I & $15(34.1)$ & $29(65.9)$ & $44(16.1)$ & 0.49 \\
\cline { 2 - 7 } & II & $26(36.1)$ & $46(63.9)$ & $72(26.3)$ & 0.36 \\
\cline { 2 - 7 } & IIIA & $20(43.5)$ & $26(56.5)$ & $46(16.8)$ & 0.07 \\
\cline { 2 - 7 } & IIIB & $17(31.5)$ & $37(68.5)$ & $54(19.7)$ & 0.56 \\
\cline { 2 - 7 } & IIIC & $12(21.1)$ & $45(78.9)$ & $58(21.2)$ & 0.02 \\
\hline \multirow{2}{*}{ Mean level of Inflammatory markers } & Hs-CRP & 7.95 & 7.65 & 7.75 & 0.6 \\
\cline { 2 - 7 } & IL-6 & 2.57 & 2.63 & 2.61 & 0.63 \\
\cline { 2 - 7 } & TNF-a & 7.09 & 6.81 & 6.9 & 0.65 \\
\hline
\end{tabular}

Totally 274 patients including 90 male and 184 female with a mean age of $28.8 \pm 14.4$ years were evaluated. Marsh classifications of samples according to patients' gender and different serum levels of investigated markers are indicated in Table 1 . The mean serum levels of hsCRP, IL-6 and TNF-a were 7.8 $\pm 3.1 \mathrm{mg} / \mathrm{l}, 2.6 \pm 0.9 \mathrm{pg} / \mathrm{ml}$ and $6.9 \pm 4.6 \mathrm{pg} / \mathrm{ml}$ respectively $(\mathrm{p}=0.60, \mathrm{p}=0.63$ and $\mathrm{p}=$ 0.65). Marsh II was the most common with a mean figure of $26.3 \%$ followed by Marsh III c (21.1\%). Female were more affected by celiac disease according to pathologic reports and in all Marsh classifications the percentages of intestinal involving among female were more than male; however, only Marsh IIIc showed a significant difference between male and female $(\mathrm{p}<0.02)$. Mean \pm SD of hs-CRP was high among patients with Marsh I with a significant relationship ( $p=0.01$ ) but other Marsh classes did not show significant relations with this marker. Serum level of IL-6 showed significant relationship with the severity of mucosal damage upon Marsh I, II and IIIC $(\mathrm{p}=0.000$, $\mathrm{p}=0.02$ and $\mathrm{p}=0.000$ respectively) but not with Marsh class IIIA and IIIB. Similar to IL6, mean \pm SD serum level of TNF-a showed significant relationship with the severity of mucosal damage upon Marsh I, II and IIIC ( $\mathrm{p}=0.03$, $\mathrm{p}=0.05$ and $\mathrm{p}=0.03$ respectively) but not with Marsh class IIIA and IIIB. There is a positive relationship between mean \pm SD serum levels of IL6 and TNF-a with different 
classes of Marsh classification from I to IIIC with the highest amounts in Marsh IIIC.

Table 2. The relationship between Mean \pm SD of different serum markers and classes of intestinal involvements in celiac patients

\begin{tabular}{|c|c|c|c|c|c|c|}
\hline \multirow{2}{*}{$\begin{array}{l}\text { Variable } \\
\text { Marsh }\end{array}$} & \multicolumn{2}{|c|}{ Hs-CRP } & \multicolumn{2}{|c|}{ IL-6 } & \multicolumn{2}{|c|}{ TNF-a } \\
\hline & Mean \pm SD & P-value & Mean \pm SD & P-value & Mean \pm SD & P-value \\
\hline I & $7.19 \pm 3.3$ & 0.01 & $1.81 \pm 0.6$ & 0.0001 & $5.07 \pm 1.3$ & 0.03 \\
\hline II & $8.19 \pm 3.1$ & 0.9 & $2.39 \pm 0.9$ & 0.02 & $5.87 \pm 2.9$ & 0.05 \\
\hline IIIA & $7.83 \pm 2.7$ & 0.1 & $2.79 \pm 0.6$ & 0.1 & $7.41 \pm 3.7$ & 0.03 \\
\hline IIIB & $8.66 \pm 2.9$ & 0.07 & $2.81 \pm 0.7$ & 0.1 & $7.33 \pm 2.3$ & 0.4 \\
\hline IIIC & $8.32 \pm 3.2$ & 0.3 & $3.16 \pm 0.6$ & 0.0001 & $8.49 \pm 3.4$ & 0.003 \\
\hline
\end{tabular}

Table 3. The cut of point scores related to different serum cytokines in comparison with Marsh classification among celiac patients

\begin{tabular}{|c|c|c|c|c|c|c|c|c|c|c|}
\hline \multirow[b]{2}{*}{ Variable } & \multicolumn{5}{|c|}{ Mean \pm 2SD $(95 \%$ CI $)$} & \multicolumn{5}{|c|}{ Cut of point } \\
\hline & $\begin{array}{c}\text { Marsh I } \\
\mathrm{N}=44\end{array}$ & $\begin{array}{c}\text { Marsh II } \\
\mathrm{N}=72\end{array}$ & $\begin{array}{c}\text { Marsh IIIa } \\
\mathrm{N}=46\end{array}$ & $\begin{array}{c}\text { Marsh IIIb } \\
\mathrm{N}=54\end{array}$ & $\begin{array}{c}\text { Marsh IIIc } \\
\mathrm{N}=58\end{array}$ & $\begin{array}{l}\text { Marsh I } \\
\mathrm{N}=44\end{array}$ & $\begin{array}{c}\text { Marsh II } \\
\mathrm{N}=72\end{array}$ & $\begin{array}{c}\text { Marsh } \\
\text { IIIa N=46 }\end{array}$ & $\begin{array}{c}\text { Marsh } \\
\text { IIIb N=54 }\end{array}$ & $\begin{array}{c}\text { Marsh } \\
\text { IIIc } N=58\end{array}$ \\
\hline \begin{tabular}{|c}
$\mathrm{IL}-6$ \\
$\mathrm{pg} / \mathrm{ml}$
\end{tabular} & $\begin{array}{c}1.8 \pm 1.3 \\
(0.5-3.1) \\
\end{array}$ & $\begin{array}{c}2.3 \pm 1.6 \\
(0.7-3.9) \\
\end{array}$ & $\begin{array}{c}2.8 \pm 1.4 \\
(1.4-4.2) \\
\end{array}$ & $\begin{array}{c}2.8 \pm 1.6 \\
(1.2-4.4) \\
\end{array}$ & $\begin{array}{c}3.3 \pm 1.1 \\
(2.2-4.4) \\
\end{array}$ & 3.1 & 3.9 & 4.2 & 4.4 & 4.4 \\
\hline $\begin{array}{l}\text { TNF-a } \\
\mathrm{pg} / \mathrm{ml}\end{array}$ & $\begin{array}{c}4.7 \pm 6.4(- \\
1.7-11.1) \\
\end{array}$ & $\begin{array}{c}6.3 \pm 6.7(- \\
0.4-13) \\
\end{array}$ & $\begin{array}{c}7.2 \pm 9.4(- \\
2.2-16.6) \\
\end{array}$ & $\begin{array}{c}8.3 \pm 17.8(- \\
9.5-26.1) \\
\end{array}$ & $\begin{array}{l}8.5 \pm 5.6 \\
(2.7-15) \\
\end{array}$ & - & - & - & - & 15 \\
\hline $\begin{array}{l}\mathrm{CRP} \\
\mathrm{mg} / \mathrm{l}\end{array}$ & $\begin{array}{l}5.8 \pm 7.1(- \\
1.3-12.9) \\
\end{array}$ & $\begin{array}{c}7.7 \pm 5.6 \\
(2.1-13.3) \\
\end{array}$ & $\begin{array}{c}7.8 \pm 5.5 \\
(2.3-13.3) \\
\end{array}$ & $\begin{array}{c}8.7 \pm 5.9 \\
(2.8-14.6)\end{array}$ & $\begin{array}{c}8.3 \pm 6.5 \\
(1.8-14.8)\end{array}$ & - & 13.3 & 13.3 & 14.6 & 14.8 \\
\hline
\end{tabular}

According to the results of this study the cut of points associated to the different serum levels of IL6 upon Marsh classification were different among celiac patients. The cut of point related to TNF-a was 15 only in Marsh IIIc and CRP serum level, similar to IL6, showed different figures upon Marsh classification (Table 3).

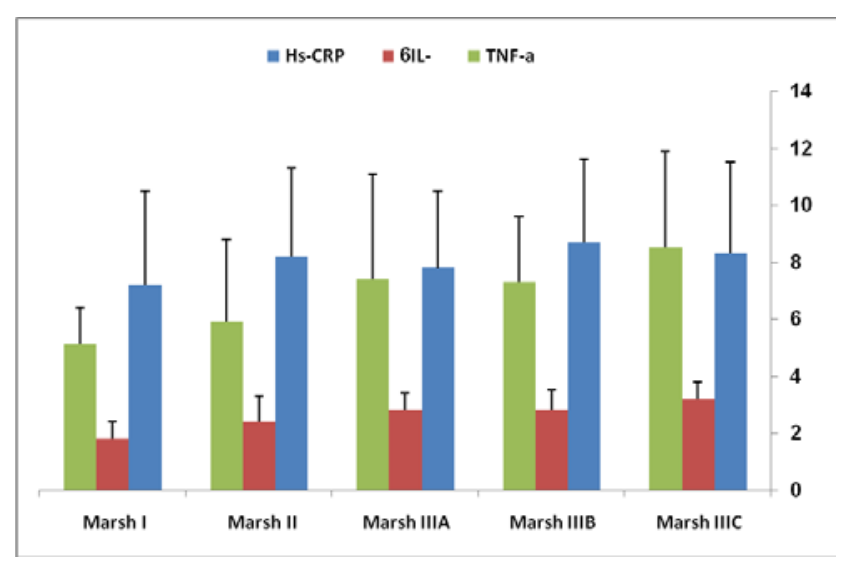

Figure 1. The relationship between serum markers and severity of intestinal involvements in celiac patients upon Marsh classification

\section{Discussion}

Celiac is caused by damages of intestinal mucosa due to sensitivity to gluten amongst susceptible individuals and intestinal biopsy samples taken from these patients show villous atrophy accompanied with crypts hyperplasia and lymphocytes secretion [14]. The accepted pathologic concept in these patients is activation of $\mathrm{T}$ cell in lamina propia and production of $\mathrm{Ab}$ with autoimmune characteristics $[15,16,17]$. Different studies have reported that gluten experimentally stimulates the production of pre-inflammatory cytokines $[13,18]$. In the current study we evaluated the variations of serum levels of inflammatory markers including hs-CRP, IL-6 and TNF-a among celiac patients and also investigated any relationship between these variations and the severity of intestinal damages upon Modified Marsh classification. The majority of participants were female, however, there was no significant difference between mean serum level of these markers among male compared to female. Mean serum level of hs-CRP was high among patients with Marsh I significantly $(\mathrm{p}=0.01)$ but other Marsh classes did not show significant relations with this marker. There was a significant relationship between serum level of IL-6 and mucosal variations upon Marsh I, II and IIIC ( $p=0.000$, $\mathrm{p}=0.02$ and $\mathrm{p}=0.000$ respectively) but not in Marsh classes of IIIA and IIIB. The same results were seen for the relations between serum level of TNF-a and mucosal variations upon Marsh classification. According to these results there is a positive relationship between serum levels of IL-6 and TNF-a with pathologic variations of intestinal mucosa upon Marsh classification. However, this phenomenon was not seen regularly for serum level of hs-CRP. There was no study so far to report the relation between serum levels of inflammatory markers and pathologic variations of intestinal mucosa among celiac patients. A study by Westerholm and others reported that the serum level of INF-y, IL-6 and IL-2 among celiac patients and susceptible individuals compared to control groups was higher [19]. Also another study showed that explanation of IL-2 gene among children with celiac disease was more than normal people [20]. Cataldo and coworkers indicated that patients with special IgA deficiency had a higher serum level of pre-inflammatory cytokines particularly the level of INF-y [21]. All associated studies have confirmed serum rising of inflammatory markers among celiac patients compared to control groups; however, the current study showed the significant and positive relation between mucosal variations and serum level of inflammatory markers.

Cytokines inflammatory markers are increased in many diseases and therefore they are nonspecific markers in diagnosis of certain diseases, however, they are used widely in the clinic to help professionals in identification of some diseases when they are accompanied by other diagnostic criteria. In the current study we showed that increasing of these markers in the serum of celiac patients is common and their levels are increased when the pathological aspects of the disease are worsen on the basis of Marsh classification. 
According to the results of this study, on the basis of mean $\pm 2 S D$ we concluded that if the serum level of IL6 in a celiac patient was more than $3.1 \mathrm{pg} / \mathrm{ml}$, with $95 \%$ confidence this patient has the celiac disease in accordance with Marsh I and if this figure was more than $4.4 \mathrm{pg} / \mathrm{ml}$, this patient has the celiac disease in accordance with Marsh IIIb or Marsh IIIc. The same interpretation could be applied for CRP serum levels; however, the cut of point related to TNF-a $(15 \mathrm{pg} / \mathrm{ml})$ was only detected correctly in Mrash IIIc. Also this study introduced some serologic cut of points for IL6, TNF-a and CRP in related to each pathologic aspect (Marsh classes) of celiac disease which can be used as non invasive tools in classification of diseases' severity among celiac patients.

This study has been performed among confirmed celiac patients and its main objective was to show any relation between mucosal variations and serum levels of inflammatory markers upon pathologic findings. Therefore other clinical features of this disease were not compared to the variations of serum levels of studied cytokines in this study and need to be investigated by further studies.

\section{Conclusion}

According to the results of this study, the severity of mucosal damages in celiac patients was associated with the changes of serum level of inflammatory markers and this process can help to find a non-invasive method for severity prediction of celiac disease and selection of proper medical interventions. Different cut of points associated to the different serum levels of IL6, TNF-a and CRP upon Marsh classification were identified among celiac patients.

\section{Acknowledgment}

We gratefully thank the School of Medicine, Ilam University of Medical Sciences and Vic Chancellor of Researches and technology for their valuable helps on this study.

\section{Funding}

This work was financially supported by Ilam University of Medical Sciences.

\section{Competing Interest}

There is no competing interest for this paper

\section{References}

[1] Hill, I.D., et al., Guideline for the diagnosis and treatment of celiac disease in children: recommendations of the North American Society for Pediatric Gastroenterology, Hepatology and Nutrition. J Pediatr Gastroenterol Nutr, 2005. 40 (1): 1-19.

[2] Smits, B.J., History of coeliac disease. BMJ, 1989. 298 (6670): 387.

[3] Holtmeier, W. and W.F. Caspary, Celiac disease. Orphanet J Rare Dis, 2006. 1: 3.

[4] Fasano, A., et al., Prevalence of celiac disease in at-risk and notat-risk groups in the United States: a large multicenter study. Arch Intern Med, 2003. 163 (3): 286-92.

[5] Pittschieler, K. and B. Ladinser, Coeliac disease: screened by a new strategy. Acta Paediatr Suppl, 1996. 412: 42-5.

[6] Ascher, H. and B. Kristiansson, Childhood coeliac disease in Sweden. Lancet, 1994. 344 (8918): 340-1.

[7] Johnston, S.D., et al., Preliminary results from follow-up of a large-scale population survey of antibodies to gliadin, reticulin and endomysium. Acta Paediatr Suppl, 1996. 412: 61-4.

[8] Grodzinsky, E., Screening for coeliac disease in apparently healthy blood donors. Acta Paediatr Suppl, 1996. 412: 36-8.

[9] Crone, J., et al., Prevalence of celiac disease and follow-up of EMA in children and adolescents with type 1 diabetes mellitus. J Pediatr Gastroenterol Nutr, 2003. 37 (1): 67-71.

[10] Hummel, M., et al., Development of celiac disease-associated antibodies in offspring of parents with type I diabetes. Diabetologia, 2000. 43 (8): 1005-11.

[11] Meini, A., et al., Prevalence and diagnosis of celiac disease in IgA-deficient children. Ann Allergy Asthma Immunol, 1996. 77 (4): 333-6.

[12] Bonamico, M., et al., Prevalence and clinical picture of celiac disease in Turner syndrome. J Clin Endocrinol Metab, 2002. 87 (12): 5495-8.

[13] O'Keeffe, J., et al., Flow cytometric measurement of intracellular migration inhibition factor and tumour necrosis factor alpha in the mucosa of patients with coeliac disease. Clin Exp Immunol, 2001. 125 (3): 376-82.

[14] Marsh, M.N., Gluten, major histocompatibility complex, and the small intestine. A molecular and immunobiologic approach to the spectrum of gluten sensitivity ('celiac sprue'). Gastroenterology, 1992. 102 (1): 330-54.

[15] Dieterich, W., et al., Identification of tissue transglutaminase as the autoantigen of celiac disease. Nat Med, 1997. 3 (7): 797-801.

[16] MacDonald, T.T. and J. Spencer, The role of activated T cells in transformed intestinal mucosa. Digestion, 1990. 46 Suppl 2: 290-6.

[17] Robert, M.E., Gluten sensitive enteropathy and other causes of small intestinal lymphocytosis. Semin Diagn Pathol, 2005. 22 (4): 284-94.

[18] Lio, D., et al., Gluten stimulation induces an in vitro expansion of peripheral blood $\mathrm{T}$ gamma delta cells from HLA-DQ2-positive subjects of families of patients with celiac disease. Exp Clin Immunogenet, 1998. 15 (1): 46-55.

[19] Westerholm-Ormio, M., et al., Inflammatory cytokines in small intestinal mucosa of patients with potential coeliac disease. Clin Exp Immunol, 2002. 128 (1): 94-101.

[20] Lahat, N., et al., Cytokine profile in coeliac disease. Scand J Immunol, 1999. 49 (4): 441-6.

[21] Cataldo, F., et al., Plasma cytokine profiles in patients with celiac disease and selective IgA deficiency. Pediatr Allergy Immunol, 2003. 14 (4): 320-4. 